University of New Hampshire

University of New Hampshire Scholars' Repository

Honors Theses and Capstones

Student Scholarship

Spring 2014

\title{
Animal-Assisted Therapy: Motives and Rewards
}

Kailee Victoria Collins

University of New Hampshire - Main Campus

Follow this and additional works at: https://scholars.unh.edu/honors

Part of the Alternative and Complementary Medicine Commons

\section{Recommended Citation}

Collins, Kailee Victoria, "Animal-Assisted Therapy: Motives and Rewards" (2014). Honors Theses and Capstones. 175.

https://scholars.unh.edu/honors/175

This Senior Honors Thesis is brought to you for free and open access by the Student Scholarship at University of New Hampshire Scholars' Repository. It has been accepted for inclusion in Honors Theses and Capstones by an authorized administrator of University of New Hampshire Scholars' Repository. For more information, please contact Scholarly.Communication@unh.edu. 
Running head: Animal-Assisted Therapy: Motives and Rewards

\author{
Animal-Assisted Therapy: Motives and Rewards \\ Kailee Collins, BS (Occupational Science) \\ Kerryellen G. Vroman PhD., OTR/L \\ University of New Hampshire
}

Key Words: volunteer, altruism, egotism, duality 


\begin{abstract}
Animal-assisted therapy is a complimentary therapy utilized in health care to provide goal-directed therapy using dogs. The purpose of this study was to understand what motivates individuals to being animal-assisted volunteering and rewards that encourage and sustain animalassisted volunteering. This mixed methods study employed quantitative methods, a demographic questionnaire and the Volunteer Motivation Index (VMI), which ranks motives most important to animal-assisted volunteers $(\mathrm{N}=15)$ and qualitative methods, a semi-structured interview $(\mathrm{N}=13)$. The participants ranked Values most important as a motive on the VMI. Social related variables were ranked low. Content analysis of the interviews yielded five themes: No Ordinary Dog, The Team, The Volunteer, Motives, and Rewards.

Animal-assisted therapy volunteers fall into a gray area in the altruistic-egotistic duality interpretation of volunteerism. Similar to volunteers in other areas they are motivated by altruism. However, they are not driven by egotistical needs such as social engagement or the gratitude of the recipient. Their rewards appear to be individually derived from the relationship with their dog. The participants expressed a strong sense pride verging on perceiving animalassisted volunteerism as elite. This stance is consistent with the construct of "pure" volunteerism" although this volunteering does not meet the criteria of pure volunteerism. Furthermore, animal-assisted therapists believe animal-assisted therapy should become a paid profession, a mindset that is much different from other volunteers. By understanding what motivates animal-assisted therapists to volunteer, healthcare organizations will be better able to support their continued participation and volunteer effort.
\end{abstract}




\section{Introduction}

Dogs have been companions for humans for centuries, known for the positive effects they have on their human partners (Brodie \& Biley, 1999). As early as 1792, dogs were used to assist professional health care workers with therapy (Brodie \& Biley, 1999; Velde, Cipriani, Fisher, 2005). Today animal-assisted therapy is a valued complementary therapy in health care, especially with people who are chronically ill and/or disabled (Barker \& Dawson, 1998; Brodie \& Biley, 1999; Kruger \& Serpell, 2006). In a diverse number of settings, such as nursing homes, rehabilitation centers, acute centers, hospice care, and psychiatric centers, research has consistently demonstrated that animal-assisted therapy has positive physiological, psychological and social benefits for recipients (Brodie \& Biley, 1999; Velde et al., 2005; Wells, 2009; Zimolag \& Krupa, 2009). However, there is minimal research about the people who spend their time and energy training and volunteering as the owners of these therapy dogs. This paper examines the motives and experiences of individuals who volunteer as animal-assisted therapists.

To understand why individuals become animal-assisted therapists, it is important to understand animal-assisted therapy. A single complete definition for animal-assisted therapy is difficult to find due to the lack of standardized terminology and procedures in this field of complementary healthcare (Kruger \& Serpell, 2006). However, there are a few characteristics that are commonly employed to define animal-assisted therapy. Animal-assisted therapy is goaldirected. The goals are usually related to the recipient's physiological, psychological or social well-being. It is also done under the supervision of a trained and certified handler, who has worked closely with his or her animal (Kruger \& Serpell, 2006).

There are approximately 2,000 certificate programs in the United States, as well as many similar programs in other countries around the world (Jalongo, Astorino \& Bomboy, 2004; 
RHMSS Pty Ltd, 2003). Animals and handlers are screened and trained according to the standards set down by different but often affiliate organizations (RHMSS, 2003). For example, Therapy Dogs International, Inc. rigorously evaluates any dog and their handler who wish to become animal-assisted therapists through temperament testing of the dog and observing how well they work as a team (Jalongo et al., 2004; Thompson, 2009). Often, the canine has to pass a formal behavioral evaluation and a basic obedience class to be considered suitable for therapy work (Jalongo et al., 2004; Kruger \& Serpell, 2006). The dog's temperament, capability, interest in working with unfamiliar humans, and ability to remain unaffected by loud noises, are all evaluated (Thompson, 2009). Though the evaluation process is often variable and subjective, it is seen as alleviating some of the concerns about animal welfare and risk management during therapy (Kruger \& Serpell, 2006). Once a dog and their handler are approved, they become certified, insured, and registered for animal-assisted therapy (Jalongo et al., 2004).

Existing information regarding animal-assisted therapy focuses on the session: the process of performing an animal-assisted therapy session, what meets the criteria of animalassisted therapy, and the observed benefits. There are curriculums, treatment plans, and/or goals revolving around the use of the dog to establish an animal-assisted therapy session (Jalongo et al., 2004; Kruger \& Serpell, 2006). Without these guidelines, the interaction between the canine and a client would be strictly considered an animal-assisted activity or visit, not a therapy session (RHMSS, 2003).

Interestingly, the focus of the criteria, training, and session is on the dog (the medium of therapy) and not on the handler, who plays a vital role as the interface between the recipient and dog. The handler is typically a volunteer, who values interpersonal skills and the desire to provide a meaningful therapy session. Volunteer and motivation research offers some insight 
into why people may participate as animal-assisted therapists. Knowing why people spend their time and effort for a cause is essential in identifying, recruiting and retaining volunteers (Burns et al., 2006; Bussell \& Forbes, 2002; Shye, 2009).

\section{Volunteerism}

As with most definitions, the definition of volunteering is socially constructed (Cnaan, Handy \& Wadsworth, 1996). Volunteering is "any activity in which time is given freely to benefit another person, group or organization. [These activities do] not preclude volunteers from benefiting from their work" (Wilson, 2000). A large portion of volunteer activity in the United States is focused on health and human services. The inclusion of volunteers into health services is growing in acceptance, with many organizations spending a considerable amount of money to identify, recruit and train interested individuals (Cnaan \& Goldberg-Glen, 1991; Brudney \& Kellough, 2000; Jamison, 2003). However, volunteers who choose to devote their time in a health related organization have many of the same motivations and expectations as other volunteers in different areas of focus. They desire to help people and belong to a group (Boezeman \& Ellemers, 2008; Cnaan \& Goldberg-Glen, 1991). They also have a sense of pride in and respect for the organization they are a part of, which helps develop their social identities as people and volunteers (Boezeman \& Ellemers, 2008). Essentially, health care volunteers are fueled to volunteer by both altruism and their perceived importance of community.

Though no external reward, such as money or a certificate, is typically sought through volunteering, the individual volunteer still benefits (Thoitis \& Hewitt, 2001). Volunteering helps enhances the individual's mental and physical health (Bowen et al., 2000; Thoitis \& Hewitt, 2001). Volunteering also brings about a sense of community and belonging (Omoto \& Snyder, 2002). It is this membership that helps increase a person's well-being, along with need 
fulfillment and emotional satisfaction (Omoto \& Snyder, 2002; Bussell \& Forbes, 2002). Working in the community also creates a shared social identity, which is valued by many volunteers (Omoto \& Snyder, 2002). This shared identity encourages and facilitates more participation in volunteering, which generates a beneficial cycle (Omoto \& Snyder, 2002).

Though benefits may be an indication of how meaningful volunteering is, the amount of effort put forth towards the activity determines how important the volunteer effort is to society (Thoitis \& Hewitt, 2001). The harder a person works or the more energy that is put forth, the more favorably that activity is seen as a volunteer effort (Cnaan et al., 1996). Research also indicates that a person's motivation is a good predictor of how often they will volunteer, and a strong predictor of volunteering in the future (Burns et al., 2006). Understanding why people volunteer, and especially what motivates them to give up their time to beneficiaries they do not know, is central for understanding the basis behind volunteerism.

\section{Motivation}

Determining which motivations are most important to volunteers is a key component of identifying, recruiting and retaining these volunteers. Most volunteers attribute altruistic motivations, such as acting on their values or gaining knowledge, as the main reasons they volunteer (Bowen et al., 2000; Bussell \& Forbes, 2002). However, egotistic motivations, such as expecting recognition or belonging to social groups, are another important reason why people volunteer (Burns et al., 2006). Differentiating and comparing altruistic and egotistic motivations is critical in determining the fundamental reasons why people volunteer.

\section{Altruism vs. Egotism}

To donate time and effort by one's own free will, one must be altruistically motivated (Bussell \& Forbes, 2002). Altruism is now considered an essential personal characteristic when 
talking about volunteering, and is expected from all volunteers (Cnaan et al., 1996). To be altruistic is to be intrinsically motivated; a person does not volunteer for the external rewards, but rather because of internal reasons, such as the desire to perform actions that benefit others (Bussell \& Forbes, 2002; Ryan \& Deci, 2000). Intrinsic motivation is the internal predisposition to seek out new challenges, and learn just to learn (Bowen et al., 2000; Ryan \& Deci, 2000).

Though altruism may seem essential to volunteering, egotistic motivation has been determined a legitimate reason why some individuals choose to volunteer (Bussell \& Forbes, 2002). These "self-oriented reasons" may be for self-enhancement, to acquire an external reward or to avoid punishment (Burns et al., 2006; Bussell \& Forbes, 2002). Egotistic motivation is also related to extrinsic motivation (Ryan \& Deci, 2000). Extrinsic motivation is when an individual performs an action or activity to receive a separate, tangible outcome (Ryan \& Deci, 2000).

Altruism has only recently been cited as an independent motivation. Previously, it was thought that behaviors which outwardly appeared altruistic were actually derived from egotistical motives (Burns et al., 2006). However, enough research indicates that it is possible for individuals to volunteer for both altruistic and egotistic reasons. The egotistic-altruistic duality is apparent in a number of studies about volunteering motivations (Bussell \& Forbes, 2002; Burns et al., 2006; Cnaan \& Goldberg-Glen, 1991; Shye, 2009). The goal that each individual hopes to reach determines whether altruism or egotism is the primary motivator (Bussell \& Forbes, 2002). Individuals can volunteer to reach psychological goals, which relates more to values and altruism, or to reach social goals, which is a more egotistical reason (Bussell \& Forbes, 2002; Burns et al., 2006). Other times, it depends on the activity done. For those who volunteer in the domain of health and human services, such as animal-assisted therapy, there is evidence that this 
duality exists (Cnaan \& Goldberg-Glen, 1991; Jamison, 2003). The primary motives and reasons behind why individuals become animal-assisted therapists will be discovered through this study.

\section{Methods}

\section{Participants and Sampling}

This mixed methods study was approved by the University of New Hampshire Institutional Review Board for the Protection of Human Subjects. Fifteen animal-assisted therapists who either volunteered in the past or are currently volunteering as animal-assisted therapists were recruited from Rhode Island and New Hampshire. Participants' ages ranged from 19 to 74 (mean age was $56, \mathrm{SD}=13.46$ ). The majority of participants $(46.7 \%, n=7)$ were in their 50's. All fifteen participants (100\%) identified themselves as White. The majority of participants $(73.3 \%, n=11)$ were married and owned their own home $(86.7 \%, n=13)$. Thirty-three percent $(n=5)$ of participants were employed part-time, $26.7 \%(n=4)$ worked full-time and 20\% (n=3) were retired. All educational levels were represented, but the majority of participants $(46.7 \%$, $n=7)$ had a graduate degree from college. Sixty-six percent $(n=10)$ of participants also reported completing other voluntary activities.

\section{Instruments}

Participants' motivations were measured by the Volunteer Motivation Inventory (VMI), a 44-item summative Likert-type rating scale from 1 (strongly disagree) to 5 (strongly agree). The VMI contains 10 categories of motivation, including Values, Reciprocity, Recognition, Understanding, Self-Esteem, Reactivity, Social, Protective, Social Interaction and Career Development (Esmond \& Dunlop, 2004). Values refers to volunteers having firm beliefs of the importance to help others and then acting on those beliefs, and Cronbach's alpha for this category was .565 (without question 38=.631). Reciprocity describes when a volunteer enjoys the 
act of volunteering and interprets it as an equal exchange, and Cronbach's alpha for this category was .729. Recognition refers to the enjoyment volunteers receive when recognized, and Cronbach's alpha for this category was .651 (Esmond \& Dunlop, 2004). Understanding refers to learning and understanding more about themselves as volunteers and the people they are assisting, and Cronbach's alpha for this category was .803. Self-Esteem describes a situation where the volunteer uses the act of volunteering to improve his or her self-esteem or self-worth, and Cronbach's alpha for this category was .831. Reactivity is when a volunteer, in order to cope with past issues, completes voluntary activities, and Cronbach's alpha for this category was .741 (Esmond \& Dunlop, 2004). Social describes when an individual volunteers because of the influence of others, and Cronbach's alpha for this category was .830. Protective describes when a volunteer escapes negative feelings about themselves through volunteering, and Cronbach's alpha for this category was .167. Social Interaction refers to when the volunteer enjoys the social atmosphere the activity creates, and Cronbach's alpha for this category was .807. Lastly, Career Development refers to when a volunteer is motivated to gain skills in order to enhance his or her career, and Cronbach's alpha for this category was .657 (without question 7=.841) (Esmond \& Dunlop, 2004).

Qualitative data was collected through a semi-structured interview. The interviews ranged from 30 minutes to an hour and a half, with an average time of 45 minutes per person. Each interview consisted of 15 core questions pertaining to the participants and their dogs, as well as animal-assisted therapy in general. These questions were designed to elicit information about participants' personality, motivation, and the relationship with their dog.

Field notes and observational notes were taken in conjunction with the interviews. During and after each interview, the reaction of each participant was noted, as well as feelings about the 
study in general. Participants were invited to voice additional information at the end of the interview, which was also documented.

\section{Procedure}

First, a packet was mailed to everyone who indicated interest in this study. The packet included an informed consent form, a demographic questionnaire, and the VMI. When the packets were returned, an appointment was set up via either telephone or email. Interviews took place in either a public restaurant or the participant's home. A digital recorder was used during every interview and the interview was then transcribed verbatim.

\section{Quantitative Results}

\begin{tabular}{|l|c|c|c|}
\hline \multicolumn{1}{|c|}{ Category } & Mean & Range & Standard Deviation \\
\hline Values & 4.5333 & 3.60 to 5.00 & .41861 \\
\hline Reciprocity & 3.7500 & 1.00 to 5.00 & .89545 \\
\hline Understanding & 3.3857 & 1.60 to 4.80 & .65044 \\
\hline Recognition & 3.3000 & 2.40 to 4.60 & .85729 \\
\hline Self-Esteem & 3.1429 & 1.00 to 4.00 & .90862 \\
\hline Social Interaction & 2.5167 & 1.25 to 3.75 & .83274 \\
\hline Career Development & 2.4167 & 1.25 to 4.25 & .63549 \\
\hline Reactivity & 2.2500 & 1.50 to 3.25 & .66533 \\
\hline Social & 2.0533 & 1.00 to 3.20 & .44078 \\
\hline Protective & 2.0000 & 1.40 to 2.80 & \\
\hline
\end{tabular}


Animal-assisted therapy combines the love of an animal and the selflessness of a human to bring joy to a person in need. In this study, the participants share a common language, ideas, and ideals regarding their involvement in animal-assisted therapy. In content analysis, five themes emerged from the participants' interviews to provide insight into how animal-assisted therapists viewed therapy, their dog, and themselves.

\section{No Ordinary Dog}

Having a well-behaved, highly trained dog is critical in an animal-assisted therapy team. Participants were quick to talk about the descriptive qualities of their dogs, making the interviews highly "dog focused". When the therapists spoke about their dog, they did so with love and pride, and described watching their dog make a client smile "[was] like [being] a parent with your kid when he gets a homerun, you just feel proud" (participant \#1). Participant \#10 expressed the same sentiment: "I absolutely loved just watching them work their magic, and then to be so proud of them." The therapists believe that since they trained their dogs, their dogs' achievements are a reflection of them, which in turn enhances their self-esteem.

The dogs' personalities, abilities, and behavior were often highlighted. Common traits ascribed to the dogs were intelligence, intuition, and a good temperament. Participant \#5 spoke about her dog's personality:

He does have a warm personality, very bubbly. He draws attention to himself...He's just got a nice, jovial personality. He goes to anyone who reflects his energy. [Therapists] want a dog that has to be friendly, a family-oriented personality. It has to be the natural personality of a dog to go to strangers.

Other participants describe their dogs as “intelligent...very well behaved and...she's very well trained" and believe most dogs "have a lot more going for them, and a lot more intelligence than people give them credit for" (participant \#7). A majority of the animal-assisted therapists are 
adamant that their dogs know they have a "job", and look forward to going to work (participant \#11). Participant \#3 admitted that "I never realized this, but when [my dog] is working, he knows he's working." Participant \#8 thinks her dogs "get a lot out of it themselves, I think they enjoy it because they seem happy to go... what dog doesn't love to be loved?” Consistently, therapists described them as "fantastic" (participant \#2), while participant \#1 made it clear that "fantastic therapy dogs [are not based] on the breed, it's the temperament of the dog and how much the owner works with the dog." Having a dog with a "good" temperament is extremely important in training a successful therapy dog, but the dog also apparently needs to be intelligent, naturally happy and easy to train.

\section{The Team}

Throughout many of the interviews, the terms "teamwork" and "trust" were often used. The bond between the therapist and his or her dog were obvious, and that bond is constantly strengthened by the joint activity of therapy sessions. It is important for the dog and the therapist to be viewed as a team. This image instills a certain professionalism and confidence that separate animal-assisted therapy teams from people who bring their animals in for visits. The therapists understand that working with their dog is essential, and one participant (\#11) even went as far as to say “he's my co-therapist, he’s my helper. I can’t imagine him not being with me.”

One key aspect of teamwork to emerge in the narratives was trust. Not only does the therapist have to trust that his or her dog is well trained and well-behaved, but the therapist also has to trust their dogs' instincts. Participant \#9, when asked about one of her best experiences, said that the best therapy sessions were when she followed her dog's lead. In regards to his dog's behavior, participant \#1 says "I'm completely at easy coming here, I have no worries whatsoever." 
Being able to trust one another can strengthen the bond of any team. Almost every participant believed that the bond that they have with their dogs is stronger from working together and helps create a better relationship. Participant \#13 said, "I think it's enhanced our bond, because we have a lot of fun and we learn a lot about each other by doing it." Participant \#8 agreed: “Once you go through all that training, you've got that bond, you know, they get so attached to you." It is clear that teamwork and trust are crucial elements to a successful animalassisted therapy relationship, and both the recipient of therapy and the team overall benefit from the strengthened connection.

\section{The Volunteer}

For many animal-assisted therapists, talking about their dog appeared to be easier than talking about themselves. Participant \#13, when asked what qualities a person should require if they were to become an animal-assisted therapist, stated "A person? Geez, if you said a dog, I'd probably have a ton." While the dog is the focus of animal-assisted therapy, it also takes certain qualities to be an effective animal-assisted therapist. A sense of responsibility and commitment were qualities many of the participants' emphasized as important when asked what qualities an animal-assisted therapist needed to have. They made it clear that a love of dogs and a caring personality are necessary to be successful.

Becoming a certified and effective animal-assisted therapist takes certain qualities and a tremendous amount of work. Participant \#1 stated that a caring nature is imperative, and he believes animal-assisted therapists "obviously want to help people, and [are] willing to do the work required." Participant \#8 echoed this sentiment, stating "If I didn't care, I don't think I'd be as good at it." Participant \#4 agreed that animal-assisted therapists "need to be caring about 
others, about people. Because if [they're] going to be doing therapy, [they] will be working with people... and [they] have to care about the people with whom [they] will be working."

Time and patience are required to train a dog to be part of the animal-assisted therapy team and to work with all different types of clientele (participant \#2). Other qualities necessary to be a good animal-assisted therapist include "understanding, patience, love of others less fortunate [and] sharing what you have" (participant \#5). Participant \#6 described the two most important qualities of being an animal-assisted therapist as "empathy and caring." It is clear from speaking with these participants that each animal-assisted therapist must be caring, empathetic, patient and genuinely invested in those that they visit.

Along with certain qualities, a sense of work ethic and commitment are essential for those who wish to be animal-assisted therapists. These qualities often determined who remained an animal-assisted therapist, and who could not continue with this particular volunteer activity. Participant \#3 felt very strongly about commitment:

If you want to commit to doing something like this, it can't be a fad. You have to commit yourself to it because you have to keep in mind that once you develop a relationship between your dog and this other person, and then you say well, uhm, I'm tired of this, I don't want to do it anymore, you have to think of the person that was getting that enjoyment form having the dog come and see him to just not showing up...you're doing them a disservice by not committing.

Participant \#11 agreed, stating "I think it's a commitment and I think you need to be very, very sure about your dog." Being a successful animal-assisted therapist requires the therapist to have specific qualities while also putting in the necessary amount time and commitment.

\section{Motivation}


As with most volunteering activities, there are no tangible rewards associated with donating time and effort to a cause. So why do people constantly volunteer? A number of participants spoke about "giving back" to the community. The motivations of giving back and being needed were compelling, and aided the therapists in their decision to become animalassisted therapists.

Many therapists explained "giving back" as doing something nice for the community that has provided them with so much. Participants felt as though, for their good fortune in life, they should give something to people less fortunate. Participant \#1 said, "I'm giving something back as opposed to just being another person, getting my paycheck...I don't have to donate money, and it's just something I can give back to the community." Participant \#11 also wanted to give back to the community, stating that she "[wanted] to create a better place...[and] a better space." Another participant, \#13, felt that volunteering was more spiritual, and "consider[ed] it a ministry”. She said, “I really want to help people. I'm not looking for a paycheck...I would like to do it until I can't do it anymore." Giving back to the community, and to those less fortunate, were important motivators for participants to pursue animal-assisted therapy.

The life stage a participant was in impacted their decision to give back. Participant \#9 said she "wanted to give back" after "a wonderful 35 years teaching and that was [her] motivation." Participant \#12, who had incorporated animal-assisted therapy into her career, still expressed a desire to give back: "I should give back a little bit, you know. I'm in my 40's. When I was in my 20's and 30's, I was always in school, so now that I have a little more time..." Participant \#3 wanted a way to volunteer without interfering with his other commitments: "I did this after I retired, so for me I had the time. And giving back has an awful lot to do with it." 
One last important motivator for participants to give back was to feel needed. Even though they were volunteering for free, they wanted to feel appreciated. Participant \#5 said, “[The first place I worked at was] a good facility to work in, but I just felt I wasn't needed enough there. So I searched to where I belonged. It's important for me and my dogs.” Many places that have a "need" for animal-assisted therapy include nursing homes and with the elderly (participant \#8). It is important for these participants to be able to give back to their community, to feel needed and appreciated while giving back, and to do something interesting to occupy their leisure time.

\section{Rewards}

The theme that emerged concerning personal reward was complex. Volunteers are thought of as selfless people who do not desire a reward. Yet it is clear from these interviews that the animal-assisted therapists involved felt rewarded for their hard work and time spent. Many participants used the words "life-changing", "magical" and "a good thing". Participant \#1 said he "never left [the facility] feeling bad" and looked forward to volunteering because "it's so different from what [he does] for a living...it's something that probably keeps [him] grounded." Participant \#5 says she "look[s] forward to it. It's a change." and that it "just changed [her] world completely". Participant \#14 was extremely enthusiastic when talking about the affect animalassisted therapy had on her life:

"It's probably been the greatest thing I've ever done. It's probably been the most inspiring and the most fun, and out of all the things I've done in my life, probably the most interesting. And I think as jobs go, if you want to call it a job...it's one of the best things to work with your best friend and go out and help people and provide society. It's just been absolutely awesome." 
Many participants spoke about the "magical" element of animal-assisted therapy. Even though the benefits of this therapy are supported by empirical evidence, almost every therapist personally expressed that there was something unique and "enchanting" about each session. Participant \#4 felt as though “it [was] simply magic.” Participant \#7 said that watching her dog interact with a client "was like watching a miracle. That was the power of pet therapy." The power of pet therapy was defined as “a feeling in your heart you can't describe, it's the real feel good thing" (participant \#8). Participant \#10 summed up her entire experience as an animalassisted therapist in one statement:

"[I felt] privileged to be part of it. I wanted to cry just seeing what he was doing with those people, it was so beautiful and amazing. That has to be one of the most memorable experiences of my life...I absolutely loved just watching them work their magic. It changed me. It changed my life."

Having the ability to work with an extraordinary dog, while having the necessary qualities, time and commitment to do so, is crucial in forming a good animal-assisted therapy team. However, it is the ability to give back to the community, and to experience the rewards associated with giving back, that make it all worth it.

\section{Discussion}

Animal-assisted therapists in this study share many of the same ideals and values as other people who volunteer in a variety of activities, but there are characteristics that are distinctive to this group of individuals. We see these similarities and differences when we view animalassisted therapists from the perspective of the altruistic-egotistic duality and volunteer continuum (Bussell \& Forbes, 2002; Burns et al., 2006; Cnaan \& Goldberg-Glen, 1991; Cnaan et al., 1996; Shye, 2009). They display the altruistic features that are consistent with volunteerism in other domains. However, the animal-assisted therapy study participants expressed motivations that 
were neither egotistic nor altruistic. They also did not rate highly the desire to partake in the social element of volunteering, which is commonly expressed by other volunteers.

Altruistic motivations, including a desire to help people and to adhere to one's values, were some of the core reasons participants gave for becoming and remaining animal-assisted therapists (Bowen et al., 2000; Bussell \& Forbes, 2002; Ryan \& Deci, 2000). Participants rated Values as the number one motivation in the VMI, with a mean score of 4.5 out of 5 . Consistent with existing studies that examine the motives of volunteers, participants expressed a deep desire to help people, and acted upon that desire in their volunteer activity (Bussell \& Forbes, 2002; Esmond \& Dunlop, 2004). What emerges from this study is participants' strong values and sense of responsibly to give back for the quality of life one has had. These desires were clearly expressed in the interviews.

Though animal-assisted therapists have altruistic motives, they appear to also have an increase in self-importance. They believe that their volunteering activity of animal-assisted therapy is significant enough to be recognized as a profession. The motivation based on the perceived importance of the volunteer activity does not satisfy the definitions of either altruism or egotism motives (Bussell \& Forbes, 2002; Cnaan \& Goldberg-Glen, 1991). Therefore, it seems as though there is a gray area that animal-assisted therapists fall into. Participants, without a doubt, have genuinely altruistic motivations, yet they also believe they are an elite group. This draws into question their true motivations and qualifications as volunteers

The authors Cnaan, Handy and Wadsworth (1996) discuss what qualifies an individual to be an authentic, or pure, volunteer, and what makes an individual a less qualified volunteer. The continuum is determined by four factors: the reason behind why they volunteered, the monetary reward, if the volunteer activity is formal or informal, and if the beneficiaries are strangers or not 
(Cnaan et al., 1996). To be considered a "pure" volunteer, one must volunteer through free will, expect no monetary reward and is willing to pay to volunteer, to volunteer through a formal, nonprofit organization, and have the beneficiaries of the volunteer activity be complete strangers (Cnaan et al., 1996). The broadly defined, or less pure, volunteer is obligated to volunteer, expects to be reimbursed or receive a stipend, informally volunteers for friends and family, and knows the beneficiaries (Cnaan et al., 1996). There is some gray area in this continuum, but those are the two extremes between which volunteers fall.

The "purer" the volunteer is, the greater the net cost of their volunteer activity. The net cost is determined by the cost minus the benefits for the volunteer (Cnaan et al., 1996). Factors that contribute to "cost" include time and effort spent, and income and social pleasure lost. "Benefits" include social participation and provided pleasurable opportunities for the volunteer to engage in (Cnaan et al., 1996). The higher the cost, or the more the volunteer has to give up, the more pure that volunteer seems.

With the participants of this study, we see an inconsistency between the definition of "pure" volunteers and the cost/benefit equation. Based on the definition, animal-assisted therapists appear to be "pure" volunteers. They volunteer from their own free will, they do not receive payment and actually pay for classes and certification, many volunteer through a formal organization or are certified by a formal organization, and many do not know the beneficiaries. However, from the standpoint of net cost versus perceived benefits, they cannot be considered the highest ranking of "pure" volunteerism (Cnaan et al., 1996). Their perception of the amount of time and effort spent towards volunteering is high, which in turn influences their perception of the importance of their volunteering activities (Cnaan et al., 1996; Thoitis \& Hewitt, 2001). However, the perceived "net cost" of volunteering for these individuals is relatively low (Cnaan 
et al., 1996). Many individuals are retired, so they are not giving up time they have could have spent working and making an income. Also, for some of those participants who do work, their dogs work with them, so income is not lost. Lastly, none of these individuals view their volunteer activity as a deterrent to social opportunities. Animal-assisted therapists believe themselves to be an "exceptionally" hard-working and committed group of volunteers and perceive themselves as distinctive, in part due to the time and effort put into training their dog and what is involved in animal-assisted therapy.

The study participants held their sense of commitment and work ethic in high regard, viewing their volunteer efforts more favorably than other volunteer activities. Many therapists believed that the volunteer act of animal-assisted therapy should become a profession. It was apparent through the tone of many interviews that the participants believe this to be a "different" kind of volunteer activity, especially due to the training, extensive education and level of commitment involved. Participants were proud of their accomplishments and the work they had done so far, and felt they should be viewed as professionals, similar to working "pro-bono". Though paid work is not the "norm" for this group, many participants believe it should be.

In regards to other volunteers, not only do animal-assisted therapists fall in a gray area of the altruistic-egotistic duality, they also seem distinctive in that the social element of participating in volunteer activities is not a motivating factor. Previous studies report volunteers express the desire to belong to a group (the social element) as a strong motivator to volunteer (Omoto \& Snyder, 2002; Bussell \& Forbes, 2002). Volunteering appears to establish a person's shared social identity (Omoto \& Snyder, 2002). This shared identity helps establish and enhance an individual's feeling of worth as a member of the community (Omoto \& Snyder, 2002). On the VMI that measure the social aspect of volunteering, Social Interaction and Social, were ranked 
low (i.e., sixth and ninth out of ten, respectively). The participants never mentioned any interest in working with other volunteers, including other animal-assisted therapists.

This therapy appears to be an individualistic volunteer activity. Though animal-assisted therapists spoke about a "team effort", they were referring to themselves and their dogs, and not working with the animal-assisted community. It might be argued that the dog replaces the shared component that other volunteers derive from fellow volunteers. As pet owners, animal-assisted therapists equated their pets to family members, and describe their pets using human characteristics (Allen, Kellegrew, \& Jaffe, 2000). By attributing human qualities to their dog, the need for social interaction with other therapists or humans is not as important (Allen et al., 2000).

\section{Limitations}

One of the limitations of this study was the small sample size that completed the VMI. Another limitation was that each individual was only interviewed once and only two observations of animal-assisted therapy teams visiting nursing homes were conducted. There is also an inherent accountability when interpreting other people's stories. However, the high number of narratives provides a favorable level of transferability to the themes found in this study.

\section{Implications}

Understanding what motivates individuals to volunteer allows organizations to design a way to identify, recruit and retain potential volunteers. Using this information specifically relating to animal-assisted therapists, institutions such as hospitals, community centers, nursing homes and schools can target and recruit animal-assisted therapists to visit and provide therapy to those who need it most. Additionally, by understanding the specific needs and motives of this 
particular group, these different settings can better support animal-assisted therapists as part of the health care team. Also, animal-assisted therapy could be implemented in conjunction with occupational therapy as a way to make treatment and interventions more fun and meaningful to animal lovers. By incorporating a more meaningful activity into a standard therapy session, participation, especially in children, the aging population, and individuals who love animals, could be increased.

\section{Conclusion}

Animal-assisted therapists demonstrate some of the altruistic-egotistic duality that is common in other volunteers, yet this unique group falls into a gray area that has yet to be explored. Also, they do not express any interest in the social aspects of volunteering. It is important to understand what motivates animal-assisted therapists in order to hopefully identify and recruit future therapists and integrate them into areas that could benefit immensely from this type of therapy. This is the first study looking at the motivation for the specific volunteer activity of animal-assisted therapy. Theoretical information to support this study was drawn from both volunteer and motivation research. However, more research should be conducted on this subject. Ethnographic research, which would comprise of observing the therapist team work, is one avenue of research that would yield rich information. 


\section{References}

Allen, J. M., Kellegrew, D. H., \& Jaffe, D. (2000). The experience of pet ownership as a meaningful occupation. Canadian Journal of Occupational Therapy, 67, 271-278.

Barker, S. B., \& Dawson, K. S. (1998). The effects of animal-assisted therapy on anxiety ratings of hospitalized psychiatric patients. Psychiatric Services, 49, 797-802.

Bautista-Chavez, A. M., Garza, A. N., Herkes, S. M., Kienast, K. J., McClendon, N. W., Sharpe, A. L. \& Houchens, B. C. (2012). Motivations of volunteer dream mentors. American Society for Engineering Education.

Boezeman, E. J. \& Ellemers, N. (2008). Volunteer recruitment: The role of organizational support and anticipated respect in non-volunteers' attraction to charitable volunteer organizations. Journal of Applied Psychology, 93, 1013-1026.

Bowen, D. J., Anderson, M. R., \& Urban, N. (2002). Volunteerism in a community-based sample of women aged 50 to 80 years. Journal of Applied Social Psychology, 30, 1829-1842.

Brodie, S. J., \& Biley, F. C. (1999). An exploration of the potential benefits of pet-facilitated therapy. Journal of Clinical Nursing, 8, 329-337.

Brudney, J. L. \& Kellough, J. E. (2000). Volunteers in state government: Involvement, management, and benefits. Nonprofit and Voluntary Sector Quarterly, 29, 111-130.

Burns, D. J., Reid, J. S., Toncar, M., Fawcett, J. \& Anderson, C. (2006). Motivations to volunteer: The role of altruism. International Review on Public and Non Profit Marketing, 3, 79-91.

Bussell, H. \& Forbes, D. (2002). Understanding the volunteer market: The what, where, who and why of volunteering. International Journal of Nonprofit and Voluntary Sector Marketing, $7(3), 244-257$. 
Cnaan, R. A. \& Goldberg-Glen, R. S. (1991). Measuring motivation to volunteer in human services. Journal of Applied Behavioral Science, 27, 269-284.

Cnaan, R. A., Handy, F. \& Wadsworth, M. (1996). Defining who is a volunteer: Conceptual and empirical considerations. Nonprofit and Voluntary Sector Quarterly, 25, 364-383.

Esmond, J. \& Dunlop, P. (2004). Developing the volunteer motivation inventory to assess the underlying motivational drives of volunteers in Western Australia. Perth, Australia: Clan WA Inc. Online at: http://www.morevolunteers.com/resources/MotivationFinalReport.pdf

Jalongo, M. R., Astorino, T. \& Bomboy, N. (2004). Canine visitors: The influence of therapy dogs on young children's learning and well-being in classrooms and hospitals. Early Childhood Education Journal, 32, 9-16.

Jamison, I. B. (2003). Turnover and tretneion among volunteers in human service agencies. Review of Public Personnel Administration, 23, 114-131.

Kruger, K. A. \& Serpell, J. A. (2006). Animal-assisted interventions in mental health: Definitions and theoretical foundations. In A. H. Fine (Ed.), Handbook on animalassisted therapy: Theoretical foundations and guidelines for practice, (2nd ed., pp. 2138). San Diego, CA: Elsevier.

Moretti, F., De Ronchi, D., Bernabei, V., Marchetti, L., Ferrari, B., Forlani, C., Negretti, F., Sacchetti, C., \& Atti, A. R. (2011). Pet therapy in elderly patients with mental illness. Psychogeriatrics, 11, 125-129. doi: 10.1111/j.1479-8301.2010.00329.x

Omoto, A. M \& Snyder, M. (2002). Considerations of community: The context and process of volunteerism. American Behavioral Scientist, 45, 846-867. doi:

$10.1177 / 0002764202045005007$ 
Ryan, R. M. \& Deci, E. L. (2000). Self-determination theory and the facilitation of intrinsic motivation, social development, and well-being. American Psychologist, 55, 68-78. doi: 10.1037/0003-066X.55.1.68

RHMSS Pty Ltd. (2003). Animal assisted therapy and young people: A review of selected literature. Retrieved from http://www.menzies.org.au/Uploads/Animal-Assisted-TherapyReport.pdf

Shye, S. (2010). The motivation to volunteer: A systemic quality of life theory. Social Indicators Research, 98, 183-200. doi: 10.1007/s11205-009-9545-3

Thoits, P. A. \& Hewitt, L. N. (2001). Volunteer work and well-being. Journal of Health and Social Behavior, 42, 115-131.

Thompson, M. J. (2009). Animal-assisted play therapy: Canines as co-therapists. In G. R. Walz, J. C. Bleuer, \& R. K. Yep (Eds.), Compelling counseling interventions: VISTAS 2009 (pp. 199-209). Alexandria, VA: American Counseling Association.

Velde, B. P., Cipriani, J., \& Fisher, G. (2005). Resident and therapist views of animal-assisted therapy: Implications for occupational therapy practice. Australian Occupational Therapy Journal, 52, 43-50. doi: 10.1111/j.1440-1630.2004.00442.x

Wells, D. L. (2009). The effects of animals on human health and well-being. Journal of Social Issues, 65, 523-543.

Wilson, J. (2000). Volunteering. Annual Review of Sociology, 26, 215-240.

Zimolag, U., \& Krupa, T. (2009). Pet ownership as a meaningful community occupation for people with serious mental illness. American Occupational Therapy Journal, 63, 126137. 